\title{
The Contrastive Analysis of the Classroom Discourse Between Novice Teachers and Experienced Teachers
}

\author{
Fen GAO \\ School of Foreign Languages, Shaanxi Normal University, Xi'an, Shaanxi, PRC \\ gaojjyy@snnu.edu.cn
}

Keywords: novice teachers, experienced teachers, classroom discourse, quantity, questioning, feedback

\begin{abstract}
As one of the vital parts in foreign language learning, more and more researchers attached importance to the teachers' classroom discourse. In order to improve novice teachers' teaching awareness, we employed video transcription and interview with six subjects as a case study to find out some empirical evidence in conducting classroom discourse. The results show that there is no significant difference in the quantity of teachers' classroom discourse yet significantly different in teachers' questioning and feedback between novice teachers and experienced teachers. As a result, teachers are suggested to encourage the students with an increase of discourse quantity, provide more referential questions for students to output their views and offer more positive feedback to inspire them in English learning.
\end{abstract}

\section{Introduction}

As one of the vital parts in foreign language learning, more and more researchers attached importance to the teachers' classroom discourse. Van Lier (1998) regards discourse analysis as a procedure to analyze the audiovisual records of interaction. And later Cheng (2009) defined it as the language generated by teachers in the organization and implementation of classroom teaching, including questioning, interacting with students and giving feedback to the students.

Teachers' classroom discourse is always a focal point since 1980s. Hakansson (1986) found that the quantity and quality of teachers' discourse influence the success of classroom teaching; different psychological effects of feedback on the students would impose different impacts on their learning motivation, thinking and self-confidence (Nunan, 1991). At home, diverse perspectives were taken to analyze teachers' classroom discourse: an empirical contrast study of English classroom discourse between Chinese teachers and foreign teachers ( $\mathrm{Hu}, 2007)$, a functional linguistic study on the differences of teachers' classroom discourse between novice teachers and proficient teachers (Yang, 2012); and Peng's (2015) study on the relationship between the classroom discourse and pedagogy.

To summarize, previous researches on classroom discourse mostly concentrate on discourse interaction in general sense, and the objects are relatively limited in the higher education. Few studies so far focus on the classroom discourse contrast in terms of quantity of teachers' talk, teachers' questioning and feedback between novice teachers and experienced teachers. The quantity of teachers' classroom discourse is related to how many words teachers make and how long their conversation takes. Teachers' questioning includes designing and asking questions according to the students' level, teaching difficulties and teaching points (Wash, 2002). Teachers' feedback refers to the verbal evaluation given by the teacher in class so as to test students' understanding, correct their errors and provide the direction for the future. Sternberg in 1999 stated that experienced teachers must have the teaching expertise in solving problems and completing the teaching tasks successfully. While novice teachers are those who lack teaching efficacy and monitoring ability in the teaching process (Fu, 2001). In this paper, novice teachers refer to those in-service teachers or normal students in internship. After 2-3 years of continuous teaching, with accumulated experience and knowledge, novice teachers are gradually developed into experienced teachers ( $\mathrm{u}$ \& Sun, 2007). 


\section{Methodology}

\section{Research Questions}

In order to improve novice teachers' teaching awareness, this empirical study focuses on two questions as follows: 1). Is there any difference between novice teachers and experienced teachers in the quantity of classroom discourse, teachers' questioning and teachers' feedback? If yes, what is it? 2). What are the implications for the teachers to promote their self-development in classroom teaching?

\section{Research Subjects}

Six senior high school English teachers from Grade one of $\mathrm{X}$ senior high school in Xi'an are selected as subjects in the study, three of which are novice teachers and the other three experienced ones. The students are all in Grade one, most of whom have learned English for at least 6 years. The description is presented as below (Table 1):

Table 1 Description of subjects

Notes: NT1 = NO.1 novice teacher, NT2 = NO.2 novice teacher and NT3= NO.3 novice teacher

\begin{tabular}{|c|c|c|c|c|c|}
\hline Teachers & Age & Gender & Teaching Years & Last degree & Title of Profession \\
\hline NT1 & 24 & Female & 1 & Master & Primary Title \\
\hline NT2 & 26 & Female & 1 & Master & Primary Title \\
\hline NT3 & 25 & Female & 1 & Master & Primary Title \\
\hline ET1 & 46 & Female & 26 & Bachelor & Senior Title \\
\hline ET2 & 48 & Female & 28 & Bachelor & Senior Title \\
\hline ET3 & 50 & Female & 30 & Bachelor & Senior Title \\
\hline
\end{tabular}

ET1 $=$ NO.1 experienced teacher, ET2 $=$ NO.2 experienced teacher, and ET3 $=$ NO.3 experienced teacher

\section{Research Instruments}

Video transcription and interview are employed to find out some empirical evidence in conducting classroom discourse. All of the videos are transcribed into textual scripts, which is aimed at collecting the data of the teachers' classroom discourse; while the interview is to find out the reasons causing those differences. SPSS 22.0 is used to analyze the data in order to discover whether there is any significant difference between two groups of teachers.

\section{Research Procedures}

The author firstly selected six subjects according to the standards of NT (novice teachers) and ET (experienced teacher). Then, ten lessons on the same topic of the same unit given by each subject of the two groups were videoed and transcribed into textual scripts. Each of the lesson lasted 40 minutes. Afterwards, the author used SPSS 22.0 to conduct an analysis about three aspects, namely, the quantity of the teachers' classroom discourse, teachers' questioning and teachers' feedback.

\section{Results and Discussion}

\section{Quantity of Teachers' Classroom Discourse}

The quantity of teachers' classroom discourse contains the teacher's talk time, students' talk time and time of other class activities, and the corresponding percentage of each is calculated in 400-minute teaching period. The specific results are shown: 
Table 2 The quantity of teachers' classroom discourse

\begin{tabular}{|c|c|c|c|c|c|c|}
\hline $\begin{array}{c}\text { Teache } \\
\text { rs }\end{array}$ & \multicolumn{2}{|c|}{$\begin{array}{c}\text { Teachers' classroom } \\
\text { talk }\end{array}$} & \multicolumn{2}{|c|}{$\begin{array}{c}\text { Students' classroom } \\
\text { talk }\end{array}$} & \multicolumn{2}{|c|}{$\begin{array}{c}\text { Other classroom } \\
\text { activities }\end{array}$} \\
\hline & $\begin{array}{c}\text { Time } \\
\text { (mins) }\end{array}$ & $\begin{array}{c}\text { Percentage } \\
(\%)\end{array}$ & $\begin{array}{c}\text { Time } \\
\text { (mins) }\end{array}$ & $\begin{array}{c}\text { Percentage } \\
(\%)\end{array}$ & $\begin{array}{c}\text { Time } \\
\text { (mins) }\end{array}$ & $\begin{array}{c}\text { Percentage } \\
(\%)\end{array}$ \\
\hline NT1 & 207 & $51.75 \%$ & 129 & $32.21 \%$ & 64 & $16.04 \%$ \\
\hline NT2 & 209 & $52.25 \%$ & 121 & $30.15 \%$ & 70 & $18.60 \%$ \\
\hline NT3 & 197 & $49.35 \%$ & 117 & $29.25 \%$ & 86 & $22.40 \%$ \\
\hline ET1 & 202 & $50.45 \%$ & 125 & $31.32 \%$ & 73 & $18.23 \%$ \\
\hline ET2 & 199 & $49.74 \%$ & 122 & $30.57 \%$ & 79 & $19.69 \%$ \\
\hline ET3 & 209 & $52.13 \%$ & 115 & $28.87 \%$ & 76 & $19.00 \%$ \\
\hline
\end{tabular}

Notes: Other classroom activities refer to those tasks completed in class, such as reading the new words, watching the video and writing down the discussion results.

As we can clearly see from Table 2, teachers' classroom discourse time of novice teachers (NT1, NT2 and NT3) are similar to that of experienced teachers (ET1, ET2 and ET3), ranging from 49.35\% to 52.25\%. We can conclude there seems no significant difference between NTs and ETs in this regard and the percentage of the teachers' classroom discourse is in fact around 50\%. Meanwhile, It is also found that teachers' discourse time is much larger than that of students, the common phenomenon in English teaching in China. Students' talk time does not differ between NTs and ETs, too, occupying around 120 minutes, or 30\%. Independent-Samples T-test on the quantity of teachers' classroom discourse (Sig. $=0.844>1$ ) has further accounted for this similarity between two groups.

As for the selection of language type used by NTs and ETs, there exists no clear difference too. Both groups of teachers admit that they mostly tend to use the target language (English) in the authentic learning context, which can be overtly shown from the scripts, so as to enlarge the language input. And occasionally both are inclined to convert into Chinese in order to demonstrate the information directly.

\section{Teachers' Questioning}

Teachers' classroom questions can be divided into display questions and referential questions (Long \& Sato, 1983). Display questions (DQ) refer to those with definite or unique answers that students can find out by referring to their textbooks, while referential questions (RQ) are defined as open ones without fixed answers, which intends to motivate students to present their opinions. Table 3 illustrates the usage distribution of DQs and RQs by two groups of teachers:

Table 3 Teachers’ questioning between novice teachers and experienced teachers

\begin{tabular}{|c|c|c|c|c|c|}
\hline Teachers & Total number & \multicolumn{2}{|c|}{ Referential questions } & \multicolumn{2}{c|}{ Display questions } \\
\hline & & Number & Percentage (\%) & Number & Percentage (\%) \\
\hline NT1 & 220 & 25 & $11.36 \%$ & 195 & $88.63 \%$ \\
\hline NT2 & 234 & 18 & $7.69 \%$ & 216 & $92.31 \%$ \\
\hline NT3 & 243 & 24 & $9.88 \%$ & 219 & $90.12 \%$ \\
\hline ET1 & 355 & 18 & $5.07 \%$ & 337 & $94.93 \%$ \\
\hline ET2 & 370 & 27 & $7.30 \%$ & 343 & $92.70 \%$ \\
\hline ET3 & 367 & 30 & $8.17 \%$ & 337 & $91.83 \%$ \\
\hline
\end{tabular}


As we can see from Table 3, both NTs and ETs ask more display questions than referential ones, in that the average percentage of NTs is $90.35 \%$ and $9.64 \%$ and average of ETs is $93.15 \&$ and $6.85 \%$. It is found that there is somewhat difference in the total number of questions raised by NTs and ETs (1092>697). The independent-samples T-test (Table 4) has further confirmed the significant difference exists between NTs and ETs $(t=-16.234$, sig $=.000<.05)$. For the RQs, there is no significance between two groups $(\mathrm{t}=-.632$, $\operatorname{sig}=4>.05)$; for DQs, there is much difference between two groups $(\mathrm{t}=-16.517$, sig $=.002<.05)$. Therefore, we can summarize both groups of teachers act similarly in the use of the referential questions, yet perform quite differently in asking display questions.

Table 4 Independent-samples T-test of teachers’ questioning

\begin{tabular}{|c|c|c|}
\hline & $\mathrm{T}$ & Sig. \\
\hline $\begin{array}{c}\text { The total teachers' } \\
\text { questions }\end{array}$ & -16.234 & .000 \\
\hline Referential questions & -.632 & 4 \\
\hline Display questions & -16.517 & .002 \\
\hline
\end{tabular}

In order to find out the underlying reasons, the author conducted a semi-structured interview with six subjects. Both NTs and ETs hold the view that the RQs are time-consuming so little time is given students to present their ideas about the specific topic. Experienced teachers hope to have students more efficiently and effectively involved in the whole process of English learning through proposing more questions. While novice teachers admit that they have less control over the class because of lacking the teaching experience and related teaching theory, so that they only bring out the limited number of RQs in order to save time and complete the scheduled tasks. This data surprisingly does not correspond to that of percentage in Table 3.

\section{Teachers' Feedback}

There are positive feedback (PF) and negative feedback (NF) according to Nunan (1991) in evaluating classroom performance and behavior. Table 5 manifests the differences in giving feedback between novice teachers and experienced teachers:

Table 5 Teachers’ feedback between novice teachers and experienced teachers

\begin{tabular}{|c|c|c|c|c|c|}
\hline $\begin{array}{c}\text { Teacher } \\
\text { s }\end{array}$ & $\begin{array}{c}\text { Total } \\
\text { number }\end{array}$ & \multicolumn{2}{|c|}{ Positive feedback } & \multicolumn{2}{c|}{ Negative feedback } \\
\hline & & Number & $\begin{array}{c}\text { Percentage } \\
(\%)\end{array}$ & Number & $\begin{array}{c}\text { Percentage } \\
(\%)\end{array}$ \\
\hline NT1 & 361 & 341 & $94.46 \%$ & 20 & $5.54 \%$ \\
\hline NT2 & 342 & 329 & $96.20 \%$ & 13 & $3.80 \%$ \\
\hline NT3 & 356 & 356 & $100.00 \%$ & 0 & $0.00 \%$ \\
\hline ET1 & 465 & 465 & $100.00 \%$ & 0 & $0.00 \%$ \\
\hline ET2 & 437 & 437 & $100.00 \%$ & 0 & $0.00 \%$ \\
\hline ET3 & 421 & 416 & $98.81 \%$ & 5 & $1.19 \%$ \\
\hline
\end{tabular}

According to the above data, we can find that the total number of teachers' feedback between NTs and ETs vary a lot from each other. NTs fluctuate around 300, while ETs are more than 400. 
However, both groups are more inclined to provide more PF than NF. The significance between two groups in PF does not show much difference, while there is indeed a significant difference in NF, the number of which for ETs is far less than that of NTs $(5<33)$. Also the independent-samples T-test (Table 6) has further testified this significant difference between NTs and ETs on the total number of teachers' feedback $(t=-6.259$, sig $=.003<.05)$. Besides, significant difference exists in terms of both positive feedback $(\mathrm{t}=-7.197$, $\mathrm{sig}=.002<.05)$ and negative feedback $(\mathrm{t}=3.713$, and Sig $=.021<.05$ ) between two groups.

Table 6 Independent-samples T-test of teachers’ feedback

\begin{tabular}{|c|c|c|}
\hline Type & $\mathrm{T}$ & Sig. \\
\hline $\begin{array}{c}\text { Total number of teachers } \\
\text { feedback }\end{array}$ & -6.259 & .003 \\
\hline Positive feedback & -7.197 & .002 \\
\hline Negative feedback & 3.713 & .021 \\
\hline
\end{tabular}

From the interview, both novice teachers and negative teachers agree that positive feedback has a greater value on learners' learning process, which accounts for their little use of negative feedback. ETs believe that when giving positive feedback, students would get more enthusiastically involved in English learning. However, for NTs, although they know positive feedback is of great help, they may fail to manage their feedback positively due to little control over the class. Both acknowledge that teachers should be more patient to the students by providing more positive feedback, through which students are becoming more confident in the foreign language learning.

\section{Conclusion}

To sum up, the study has concluded that there is no significant difference in the teachers' classroom discourse between novice teachers and experienced teachers. Both groups adopt English as the class language in the vast majority of time for strengthening the language input and occasional use of Chinese for more direct information transference. Yet, there is indeed a significant difference in total number of questions and in asking display questions, while not in asking referential questions. Lastly, there exists a significant difference between two groups in teachers' positive and negative feedback, and they both agree that positive feedback has greater impacts on learners' learning than negative one.

In the future language teaching, we could encourage teachers to guarantee the quality of the quantity of teachers' classroom discourse. On this premise, teachers should provide more referential questions for students to output their views. It must be pointed out teachers should cater the difficulty of the questions for different levels of the students. The last but not the least, teachers must present more positive feedback to inspire students in English learning, which can enrich them with more confidence and harmony with each other.

\section{References}

[1] L. Van Lier, The relationship between consciousness, interaction and language learning. Language Awareness, 7 (1998)128-145.

[2] X. T. Cheng, An Analysis of English Teachers' Classroom Discourse, Shanghai Foreign Language Education Press, 2009. 
[3] G. Hakansson, Quantitative studies of teacher talk. In Kasper (ed.). Learning, Teaching and Communication in the Foreign Language Classroom, Aarhus University Press, 1986.

[4] D. Nunan, Communicative tasks and the language curriculum, TESOL Quarterly, 25(1991) 279-295.

[5] Q. Q. Hu, The contrastive analysis of English classroom discourse between Chinese teachers and foreign teachers: a case study, Foreign Language Teaching Abroad, 1(2007)32-37.

[6] X. Y. Yang, The discourse analysis from the perspective of systematic functional linguistics, Foreign Language Education, 2(2012)31-36.

[7] J. Peng, Teachers' awareness of classroom discourse from the perspective of functional linguistics, Journal of Xi'an International Studies University, 2(2015)70-73.

[8] S. Wash, Construction or obstruction: teacher talk and learner involvement in EFL classroom, Language Teaching Research, 6(2002)3-23.

[9] R. J. Sternberg, Intelligence as developing expertise, Contemporary Educational Psychology, 24(1999)359-375.

[10] D. C. Fu, The new course and changes of teachers' conducts, People's Education, 12(2001)32-33.

[11] L. Yu \& Q. L. Sun, An analysis of foreign teachers' development, Education Science, 2(2007)61-66.

[12] M. Long, \& C. Sato, Classroom foreigner talk discourse: forms and functions of teachers’ questions. In H. Seliger, \& M. Long (Eds.), Classroom-Oriented Research in Second Language Acquisition (pp. 268-286). Rowley, Newsbury House, 1983. 